\title{
Deane Smith and Powder Diffraction
}

Professor Deane K. Smith has served as Editor-in-Chief of the journal Powder Diffraction for the past thirteen years. Deane was a co-founder of the journal which was first published in 1986. Under his leadership as the Editor-in-Chief, many changes and improvements have occurred. The goals and philosophy for the journal have expanded beyond the original idea of encouraging papers containing diffraction data to emphasizing technical papers on the theory and practice of diffraction for material characterization. The scope now includes not only $\mathrm{X}$-ray diffraction, but also neutron and electron diffraction as well as X-ray fluorescence.

Since diffraction is used all over the world, the journal coverage under Deane's leadership reflects this universality in the papers it has published. The 12 papers which appeared in the first issue published in March 1986 had several authors from outside North America, including Europe and Japan. To cover the large number of papers now submitted to the journal from all over the world, the editorial staff started with the Editor-in-Chief, a Department Editor and a Managing Editor, and now has expanded to include an Editor for New Diffraction Data, four Geographical Editors from Western Europe, Eastern Europe, Southeast Asia and Japan.

It has been a busy and productive 13 years for Deane. Many fine papers from all over the world have been published in the 52 issues from 1986 to 1998. The international nature of the journal was also emphasized by the publication of a Chinese edition translated and distributed by Professor Shao-Fan Lin of Nankai University in China.

In recognizing the importance of maintaining the high quality of the papers that are accepted and published in Powder Diffraction, Deane has developed detailed editing procedures for the journal. These procedures assist both the editor in judging the value of a manuscript within the scope of the journal and also the author(s) to present the results in the very best form. The procedures also ensure all information in the manuscript to be privileged and proprietary to the reviewer(s), the editor and the author(s).

Journal subscriptions now reach about 50 countries throughout the world. One of the goals for Powder Diffraction is to maintain its subscription rates low enough to en- courage diffractionists and material scientists to subscribe personally. The initial subscription price for personal subscriptions was US\$32.50 for North America and US\$48.50 for overseas delivery. These rates have now been raised reluctantly to US\$60.00 and US\$85.00, respectively. Institutions and library rates are US\$105.00. These rates are still far lower than most technical journals. The continued support and subsidies from the International Centre for Diffraction Data (ICDD) have allowed these rates to remain low.

Deane has been very active in ICDD activities for as long as I can remember. He served on the Board of Directors for 16 years from 1976 to 1992 . He was the Chairman of the Board for 8 years including 1986 when Powder Diffraction was first published.

He also has established a close relationship between Powder Diffraction and the journals of the International Union of Crystallography, primarily the Journal of Applied Crystallography. Several manuscripts, whose topics seemed more appropriate for the other journal, are transferred among the editors. Lists of manuscripts in progress are now exchanged between the editors of these journals on a regular basis.

Deane is Professor Emeritus of the Department of Geosciences at the Pennsylvania State University. He has over 40 years experience in X-ray powder diffraction of minerals, ceramics and related materials. He was presented the 1991 Barrett Award by the Denver X-Ray Conference "for his leadership in X-ray powder diffraction analysis in modeling powder diffractograms from crystal structures, advancing quantitative XRD analysis, and co-founding and editing the journal Powder Diffraction.',

The journal owes much to Deane for his outstanding contributions and leadership as its first Editor-in-Chief. We are also delighted that he will remain active and serve as an Editor for Reviews and Reprints for Powder Diffraction. Thank you very much Deane Smith.

Ting C. Huang Editor-in-Chief 